\title{
BOURSES DE RECHERCHE S.A.L.F. 2002
}

Société d'Andrologie de Langue Française (S.A.L.F)

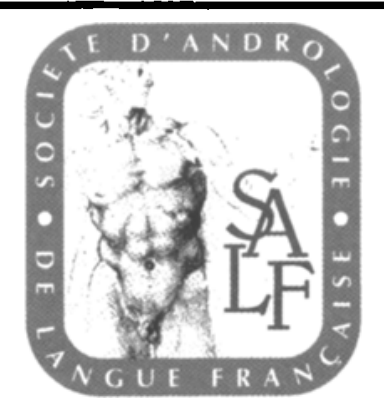

\section{SOUTIEN DE 2 TRAVAUX DE RECHERCHE DANS LE DOMAI- NE DE L'ANDROLOGIE}

\section{BOURSE DE 14000 EURO 1 BOURSE dE 7000 EURO}

\section{Conditions de candidature}

- $\quad 35$ ANS

- Fondamentaliste ou

- Clinicien francophone

\section{Ouvert à tous}

- ThÈSE D'UnIVERSITÉ

- Non STAtutaire

\section{Dossier de Candidature :}

- En 3 exemplaires, à adresser au Secrétaire de la SALF* avant le 15 Janvier 2002.

- Curriculum Vitae, principales publications, exposé du projet de recherche (4 pages maximum), attestation du Laboratoire d'accueil.

\section{CALENDRIER :}

- 15 Avril : Examen des dossiers par le Conseil d'Administration de la SALF + 2 experts extérieurs.

- 30 Juin : Désignation des 2 Lauréats et remise de la moitié du montant de la bourse.

- Décembre 2002 : Présentation du travail et remise du second versement lors du XIXème Congrès de la SALF à Genève.

- Décembre 2003 : Présentation des conclusions du travail lors du XXème Congrès de la SALF.

* Hervé LUCAS,

Maternité HUG, $30 \mathrm{Bd}$ de la Cluse, 1211 GENEVE 14, SUISSE.

Fax : 0041223824385 e-mail : herve.lucas@hcuge.ch. Site Internet : http://rockefeller.univ-lyon1.fr/salf 